\title{
Factors associated with patient's preference in choosing their therapy for inflammatory bowel disease in Brazil
}

\author{
Adhan Amenomori WU' 1 , Jaqueline Ribeiro de BARROS ${ }^{1}$, Madhoor RAMDEEN², \\ Julio Pinheiro BAIMA ${ }^{1}$, Rogerio SAAD-HOSSNE ${ }^{3}$ and Ligia Yukie SASSAKI ${ }^{1}$
}

Received: 26 August 2020 Accepted: 11 Septembrer 2020

\begin{abstract}
Background - Biological therapy and new drugs have revolutionized the treatment of inflammatory bowel disease. Ideally, the choice of medication should be a shared decision with the patient, aiming at greater satisfaction, compliance, and consequently, favorable clinical outcome. Objective - This study aims to evaluate patient's preferences in the choice of their therapy and the factors that influence this choice. Methods - This cross-sectional study enrolled 101 outpatients with Crohn's disease or ulcerative colitis. The inclusion criteria were age $\geq 18$ years and no previous exposure to biological therapy. Patients' preferences were assessed through questions that addressed the preferred mode of administration (oral, subcutaneous, or intravenous) and the factors that determined the choice of medication (efficacy, medical indication, fear of medication, convenience, mode of application, and personal doctors' indication). Results - The mean age was $43.6 \pm 13.5$ years, $75.3 \%$ were female, and $81.2 \%$ were cases of ulcerative colitis. Regarding the mode of administration, the majority of patients preferred oral (87.1\%), followed by intravenous (6.93\%) and subcutaneous (5.94\%) medications. The reasons were "I prefer to take it at home" (42.57\%), "I have more freedom" (36.63\%), "I don't like self-application" (29.70\%), and "I believe it works better" (19.80\%). Younger patients and patients in clinical disease activity preferred intravenous mode compared to the oral route $(P<0.05)$. Doctor's opinion $(98 \%)$ was an important factor associated with the medication choice. Conclusion - Oral route was the preferred mode of administration and most patients took their physician's opinion into account in their choice of medication.
\end{abstract}

HEADINGS - Biological therapy. Drug administration routes. Ulcerative colitis. Crohn disease. Inflammatory bowel diseases.

\section{INTRODUCTION}

The treatment of inflammatory bowel disease (IBD) has changed dramatically in the past 20 years. Biological therapy, and new drugs such as small molecules have revolutionized the outcome of the disease by promoting clinical remission and mucosal healing. They have contributed to better control of the disease and superior quality of life and functional capacity.

The medications currently available for the treatment of IBD patients are conventional therapy (aminosalicylates and immunosuppressants), biological therapy, and more recently, small molecules. Biological therapy consists of anti-tumor necrosis factor (TNF) agents such as adalimumab, certolizumab pegol, golimumab and infliximab; integrin receptor antagonists such as vedolizumab and natalizumab; and IL-12 and IL-23 antagonist such as ustekinumab. Tofacitinib is a small molecule (Janus kinase inhibitor) that is approved for the treatment of adult patients with moderate to severe active ulcerative colitis. These medications have been shown to induce and maintain clinical and endoscopic remission in patients with moderate to severe ulcerative colitis ${ }^{(1-5)}$ or Crohn's disease ${ }^{(6-10)}$, besides promoting healing of fistulae ${ }^{(11-14)}$. The medications differ from each other in the mechanism of their action and other aspects such as mode of administration (oral, subcutaneous [SC], or intravenous [IV]), and safety profile.

The choice of medication from the patient's perspective is based on drug efficacy, safety concerns, and patient's preference, besides convenience of administration, drug availability, and speed of action. Consequently, patient involvement in the decision-making process has emerged as one of the pillars of treatment. Patient's often feel empowered when they are given the opportunity to make treatment decisions alongside their doctor or nurse. Patient's participation in choosing their medication can result in greater satisfaction $^{(15)}$, compliance, and, therefore, favorable health outcomes. Despite these, patient centered care and shared decision making are concepts that are yet to fully find traction in many developing countries, including Brazil. Herein, this study aimed to evaluate patients' preferences in choosing their therapy and the variables that influence this choice, in a single center in Brazil.

\section{METHODS}

\section{Study design and population}

This cross-sectional study enrolled 101 consecutive IBD outpatients between August 2017 and July 2018 from a public IBD center 
in São Paulo State, Brazil. IBD diagnosis was based on clinical, endoscopic, radiologic, and histological criteria ${ }^{(16)}$. The inclusion criteria were age $\geq 18$ years, presence of confirmed IBD and no previous exposure to biological therapy (infliximab, adalimumab, certolizumab pegol, golimumab, vedolizumab or ustekinumab) or tofacitinib, in any dose or at any time during the follow-up, or previous indication for use of any of these medications. The exclusion criteria were previous exposure to biological therapy or small molecules, or refusal to participate.

The sample size was based on a convenience sample. During the study period, 317 IBD patients were treated at the center (181 UC / 136 CD), including 176 (137 UC / 39 CD) eligible for the study (bio-naive). One hundred and forty-one patients were not eligible due to previous or current use of biological therapy, most of them with Crohn's disease $(68.79 \%)$. Overall, 102 patients were invited to participate, and 101 patients (82 UC / 19 CD) were enrolled in the study. One patient was excluded due to not having IBD.

The study was approved by the Research Ethics Committee - Botucatu Medical School (CAAE: 71285417.5.0000.5411). All participants received explanations about the study objectives and expected results and were enrolled in the study only after signing the informed consent form.

\section{Clinical evaluation}

Data collected included age, sex, occupation, schooling, smoking status, duration of disease and current medical treatment. The Crohn's Disease Activity Index (CDAI) ${ }^{(17)}$ and the Montreal classification $^{(18)}$ were used to assess disease activity and extension of disease, respectively, in patients with Crohn's disease. Patients were classified in remission ( $\leq 150$ points), mild (151-219 points), moderate $(220-450$ points) or severe ( $>450$ points) clinical disease activity ${ }^{(17)}$. Disease extent and clinical disease activity were assessed by using the Mayo score ${ }^{(19)}$ for patients with ulcerative colitis. Patients were classified in remission ( $0-2$ points), mild (3-5 points), moderate (6-10 points) or severe (11-12 points) clinical disease activity ${ }^{(19)}$. The extent of intestinal damage in ulcerative colitis (proctitis, left-sided colitis, or extensive/pancolitis) ${ }^{(20)}$ was determined by reviewing their first colonoscopy report.

\section{Evaluation of patient's preference in choosing therapy}

Patients' preference was assessed through a specific questionnaire formulated for this study. The questionnaire was not validated. The questions were asked by the authors and based on the most frequent doubts experienced during the clinical consultation. The questionnaire was applied in Portuguese to all patients in the sample, in the form of an interview, regardless of economic class or level of education (supplementary material). All patients were provided information regarding available options for therapy, their risks, benefits, and side effects prior to administering the questionnaire. The questionnaire included the following questions:

Question 1. In the hypothetical case of the need to use biological therapy or new drugs, which mode of administration would you prefer? (Considering the same efficacy for all the medications): a. orally; b. IV; c. SC.

Question 2. In the hypothetical case of the need to use biological therapy, which medication would you prefer? a. Medication " $A$ " (adalimumab), consisting of induction therapy with four injections at week 0,2 injections at week 2 followed by $1 \mathrm{SC}$ injection every 2 weeks, administered at home by yourself, a nurse or a trained personnel. b. Medication "I" (infliximab), consisting of induction therapy with IV infusion at weeks 0,2 and 6 and then infusions every 8 weeks in the hospital. Each infusion is administered over 2-3 hours.

Question 3. What factors influence you to choose this medication? See FIGURE 1.

\begin{tabular}{|l|}
\hline a. I believe it works better than other medications \\
\hline b. I am afraid of SC injection \\
\hline c. I believe I will have more freedom using this medication \\
\hline d. I do not like the idea of self-application \\
\hline e. I prefer to take medications at home \\
\hline f. I prefer to take the medication at the hospital \\
\hline g. I trust this medication \\
\hline h. It was my doctor's recommendation \\
\hline i. It was the opinion of my nurse \\
\hline j. It was a referral from a friend \\
\hline k. I have seen on the internet \\
\hline
\end{tabular}

FIGURE 1. What factors influenced your choice of this medication? Choose as many as you see fit.

\section{Statistical analysis}

Data were expressed as mean \pm standard deviation or median (range) for continuous variables, and as frequency (proportion) for qualitative variables. Chi-square test and Fisher's exact test, as appropriate, were used to compare categorical data. Continuous data were compared using ANOVA and Tukey's multiple comparison test. A $P$-value of $<0.05$ was considered statistically significant. Statistical analyses were performed by using SAS version 9.3 for Windows (SAS Institute Inc., Cary, NC, USA). All authors had access to the study data. The statistical review of the study was performed by a biomedical statistician.

\section{RESULTS}

Overall, 102 patients were invited to participate, and 101 patients were enrolled in the study. One patient was excluded due to not having IBD. Mean patient age was $43.6 \pm 13.5$ years and $75.3 \%$ were female; mean disease duration was $9.75 \pm 8.09$ years. Most patients reported low/medium schooling (elementary and middle school, and high school) and low income. The socio-demographic characteristics of the patients are shown in TABLE 1.

Regarding the clinical characteristics of the patients, $82(81.2 \%)$ presented with ulcerative colitis and 19 (18.8\%) with Crohn's disease. The medications in use were mesalazine (50.5\%), azathioprine $(30.7 \%)$, and prednisone $(7.92 \%) ; 7.92 \%$ were not on any medication. Disease classification and clinical activity are shown in TABLE 2. Most of the patients were in clinical remission (UC: $67.1 \%$ and CD: $84.2 \%$ ). The average Mayo score was $2.23 \pm 2.59$ points and the average CDAI score was $98.0 \pm 77.9$ points.

\section{Preference for the mode of administration (oral vs IV vs SC)}

The majority of patients $(87.1 \%)$ preferred the oral route of administration followed by IV (6.93\%) and SC (5.94\%) administration. There was an association between the preferred mode of administration and patient's age: younger patients preferred IV 
TABLE 1. Socio-demographic characteristics of patients.

\begin{tabular}{lc}
\hline & IBD patients $(\mathbf{n}=101)$ \\
\hline Age, years & $43.6 \pm 13.5$ \\
Gender female & $76(75.3)$ \\
Disease duration, years & $9.75 \pm 8.09$ \\
Active smoking & $3(2.97)$ \\
Per capita income (BRL, US dollar) & $59(58.4)$ \\
Catholic religion & \\
Schooling & $19(18.8)$ \\
Elementary school & $19(18.8)$ \\
Middle school & $37(36.63)$ \\
High school & $25(24.73)$ \\
Higher education & $1(0.99)$ \\
No education & $58(57.4)$ \\
Employee & $69(68.32)$ \\
Consensual union & $68(67.3)$ \\
Internet access & $32(31.7)$ \\
Health professional in the family & $40(39.6)$ \\
Previous experience with & $92(91.1)$ \\
self-administration &
\end{tabular}

Data expressed as frequency (\%) and mean \pm SD. IBD: inflammatory bowel disease; BRL: Brazil currency. *Value corresponding to 1.12 minimum wages in Brazil.

TABLE 2. Classification and clinical disease activity of patients.

\begin{tabular}{lcc}
\hline & $\begin{array}{c}\text { Ulcerative colitis } \\
(\mathbf{n}=82)\end{array}$ & $\begin{array}{c}\text { Crohn's disease } \\
(\mathbf{n}=19)\end{array}$ \\
\hline Ulcerative colitis & $32(39.0)$ & \\
Distal colitis & $17(20.7)$ & \\
Left-sided colitis & $33(40.3)$ & \\
Pancolitis & & \\
Montreal classification & & 0 \\
Age at diagnosis & & $13(68.4)$ \\
A1: $<17$ years & & $6(31.6)$ \\
A2: $17-40$ years & & $7(36.8)$ \\
A3: $>$ 40 years & & $3(15.8)$ \\
Location of the disease & & $9(47.4)$ \\
L1: ileal & & \\
L2: colonic & & $9(47.4)$ \\
L3: ileocolonic & & $7(36.8)$ \\
Disease behavior & & $3(15.8)$ \\
B1: inflammatory & & $3(15.8)$ \\
B2: stricturing & & \\
B3: penetrating & & $16(84.2)$ \\
Perianal disease & & $0.5)$ \\
Clinical disease activity & & \\
Remission & & \\
Mild & & \\
Moderate & & \\
Severe & & \\
\hline
\end{tabular}

Data expressed as frequency $(\%)$. mode compared to the oral route $(P=0.01)$ (TABLE 3$)$. There was no association between the preference for the mode of administration and the type of IBD, sex, schooling, occupation, or marital status. Most patients who opted for the IV mode of administration had clinical disease activity $(85.7 \%)$. Regarding the classification of disease activity, most patients who opted for the oral mode of administration were in clinical remission $(75 \%)$, while the patients who opted for IV $(71.4 \%)$ and SC $(50 \%)$ routes were in mild disease activity $(P=0.0005)$ (TABLE 3$)$.

The main factors that patients reported as important when choosing the mode of administration were: "doctor's recommendation" (98.02\%), "I prefer to take it at home" (42.57\%), "more freedom with the use of oral or SC medication" (36.63\%), "I do not like self-administration" (29.70\%), "I believe this medication works better" (19.80\%), and "I am afraid of SC injection" (17.82\%). None of the patients based their choice on the information available on the internet.

\section{Preference for specific medication}

In a hypothetical scenario of choosing between two medications, adalimumab or infliximab, which were the only options for biological therapy available during the study period, majority of the patients chose infliximab therapy $(54.5 \%)$. The choice of adalimum$\mathrm{ab}$ (SC injection) or infliximab (IV infusion) medication was not influenced by the clinical or socio-demographic variables, diagnosis $(P=0.49)$, disease duration $(P=0.99)$ or presence of clinical activity $(P=0.65)$. The presence of a health professional in the family was more frequent in the adalimumab group $(43.5 \%$ vs $21.8 \%, P=0.02)$. The main factors that influenced the choice of medication were (adalimumab vs infliximab): fear of SC injection $(6.52 \%$ vs $27.3 \%$, $P=0.007)$, more freedom $(54.4 \%$ vs $21.8 \%, P=0.0007)$, "I do not like self-application" $(2.17 \%$ vs $52.7 \%, P<0.0001)$ and "I prefer to take medications at home" $(56.5 \%$ vs $30.9 \%, P=0.01)$.

\section{DISCUSSION}

IBD is a complex disease with variable outcomes. Favorable outcomes in the form of good disease control depend on the collaboration between a pragmatic and well-prepared multidisciplinary IBD team, and a well-informed and proactive patient. Given the diversity of therapeutic options available, with their different mechanisms of action and routes of administration, knowledge of patient preferences ensures compliance, and therefore, treatment efficacy and response rates. The present study indicates that Brazilian IBD patients preferred oral over SC or IV medication and considered doctor's opinion as an essential factor that influenced their choice of treatment.

Fear of SC injection was one of the most common reasons cited by patients when choosing their therapy. Patients are uncomfortable with self-injections at home, and therefore, prefer either oral medications at home or IV medications in the hospital. Patients appear to consider the route of administration more important than other factors, such as the presence of side effects, in the choice of therapy. Patients' confidence in medical prescription also deserves special attention since most of them follow physicians' recommendations without any restrictions.

In the first study that analyzed patient preference in selecting one anti-TNF agent over the others (CHOOSE TNF TRIAL) ${ }^{(21)}$, the authors listed the following items cited by patients as being important: side effect profile $(76 \%)$, physician's recommendation 
TABLE 3. Preference for the mode of medication administration according to the clinical characteristics and patient's opinion.

\begin{tabular}{|c|c|c|c|c|}
\hline & Oral $(n=88)$ & Intravenous $(\mathrm{n}=7)$ & Subcutaneous $(n=6)$ & $P$ \\
\hline Age, years & $45.1 \pm 13.3^{b}$ & $32.3 \pm 11.5^{\mathrm{a}}$ & $34.3 \pm 10.1^{\mathrm{a}, \mathrm{b}}$ & 0.01 \\
\hline Gender female & $67(76.1)$ & $5(71.4)$ & $4(66.7)$ & 0.67 \\
\hline Per capita income, BRL & $1096.8 \pm 924.6$ & $1000.7 \pm 436.1$ & $765 \pm 239.7$ & 0.46 \\
\hline \multicolumn{5}{|l|}{ Disease } \\
\hline Crohn's disease & $18(20.5)$ & $1(14.3)$ & $0(0)$ & \\
\hline Ulcerative colitis & $70(79.5)$ & $6(85.7)$ & $6(100)$ & 0.73 \\
\hline Clinical disease activity & $38(43.2)$ & $6(85.7)$ & $4(66.7)$ & 0.07 \\
\hline \multicolumn{5}{|l|}{ Clinical disease activity classification } \\
\hline Remission & $66(75)$ & $1(14.3)$ & $2(33.3)$ & \\
\hline Mild & $13(14.8)$ & $5(71.4)$ & $3(50)$ & \\
\hline Moderate & $8(9.1)$ & $0(0)$ & $1(16.7)$ & \\
\hline This route works better & $12(13.6)$ & $5(71.4)$ & $3(50)$ & 0.0002 \\
\hline Fear of subcutaneous injection & $18(20.5)$ & $0(0)$ & $0(0)$ & 0.35 \\
\hline More freedom with this route & $33(37.5)$ & $0(0)$ & $4(66.7)$ & 0.04 \\
\hline I don't like self-application & $28(31.8)$ & $2(28.6)$ & $0(0)$ & 0.33 \\
\hline I prefer to take it at home & $39(44.3)$ & $1(14.3)$ & $3(50)$ & 0.30 \\
\hline I prefer to take it at the hospital & $2(2.27)$ & $0(0)$ & $0(0)$ & 1.0 \\
\hline I trust this route of medication more & $4(4.55)$ & $0(0)$ & $1(16.7)$ & 0.30 \\
\hline It was the doctor's recommendation & $86(97.7)$ & $7(100)$ & $6(100)$ & 1.0 \\
\hline It was the nurse's recommendation & $0(0)$ & $0(0)$ & $0(0)$ & - \\
\hline
\end{tabular}

a,b Different letters show statistical difference between groups. Data expressed as frequency (\%) and mean \pm SD. BRL: Brazil currency; CDAI: Crohn's disease activity index.

$(66 \%)$, route of administration (54\%), and drug efficacy supported by available literature $(52 \%)$. The difference between this study and our study in terms of the main concerns of patients may be explained by the socio-cultural difference between patients. Brazilian patients in public health centers tend to be passive and are not used to participating in the choice of treatment. Efforts to educate and empower patients should be encouraged in working towards patient-centered healthcare, and to improve the doctor-patient relationship. Regarding the choice between injectable medications, Western studies that included patients with IBD ${ }^{(21)}$ and rheumatoid $\operatorname{arthritis}^{(22,23)}$ reported a preference for anti-TNF agents administered by the SC rather than the IV mode, mainly owing to its convenience. In contrast, a large number of anti-TNF-naive Korean patients preferred IV anti-TNF rather than SC anti-TNF mainly owing to a dislike of the idea of self-injecting $(73.4 \%)^{(24)}$. Similar results were also observed in Irish IBD patients ${ }^{(25)}$. Likewise, young Brazilian patients preferred IV infusion, and their main reason for this choice was their belief that IV medications work better. There are several hypotheses for this choice, although they have not been evaluated specifically for this study. Patients believed that IV medications have a faster and more effective onset of action when compared to other routes of administration. Rapid onset of action is an important requirement, especially for young people. Another important reason for choosing IV medications is in expectation of a closer contact with the IBD team, with the presence of a doctor during the infusion.
A study conducted by Almario et al. ${ }^{(26)}$ demonstrated a difference between Crohn's disease and ulcerative colitis patients in terms of the factors that determined the choice of a medication or route of administration. The study included 304 patients with ulcerative colitis and 336 patients with Crohn's disease. Therapeutic efficacy was the deciding factor among Crohn's disease patients (OR 1.41, 95\% CI 1.01-2.00); safety profile was the main factor among ulcerative colitis patients (OR 1.63, 95\% CI 1.16-2.30). This suggests that patient preferences for therapeutics are highly personalized ${ }^{(26)}$. Overall, in making these decisions, treatment efficacy is the most important category considered by patients $(41.3 \%)$, followed by side effect profile $(38.3 \%)$, mode of administration $(20.0 \%)$, and mechanism of action $(0.5 \%)^{(26)}$.

A recent study performed in Canada ${ }^{(27)}$ measured the importance of various factors related to the choice of different medications for maintenance therapy in Crohn's disease patients. The medications tested were infliximab, infliximab + azathioprine, adalimumab, vedolizumab, azathioprine, and methotrexate. The main attributes included efficacy, presence of adverse events requiring stopping the medication, such as potential toxicity, infection, and cancer, and dosing regimen. Maintenance of remission was the most important attribute considered by patients, and this reason was 2.5 times more frequent than withdrawal due to an adverse event. Among the various biologic agents, adalimumab was preferred to infliximab as well as infliximab + azathioprine. The preferences for adalimumab and infliximab + azathioprine 
over other medications was owing to their higher rates of remission, whereas the preference for vedolizumab was based on its safety profile.

Specialized IBD nurses can help patients understand the mechanism of action, mode of administration and risk-benefits of each medication, assisting in the choice of medication. The European Crohn's and Colitis Organization (ECCO) consensus ${ }^{(28)}$ recommends that patients with IBD should be accompanied by a multidisciplinary team, wherein the role of the nursing professional is to guide the patient in the choice of medication, and promoting patient empowerment in treatment-related decision-making. In the present study, patients did not have contact with the IBD nurse prior to the research, which explains some considerations about the choice of medications, such as fear of injection and the belief that intravenous drugs work better, justifying the need of the multidisciplinary team in the management of IBD patients. Brazil lacks nursing teams trained in IBD management. The barriers that need to be overcome in IBD nursing are manpower shortage, and a lack of incentives and education.

Patient-centered communication and shared decision-making are essential to the success of IBD treatment. The Institute of Medicine (IOM), USA, defines patient-centeredness as "providing care that is respectful of and responsive to individual patient preferences, needs, and values, and ensuring that patient values guide all clinical decisions"(29). The attributes of patient-centered care include: patient education and empowerment; patient-centered communication including the explanation of treatment options; including patients in treatment decisions as reflected by their values, preferences, and needs; and provision of emotional support such as relieving fear and anxiety and addressing mental health issues ${ }^{(30)}$. Gastroenterologists and IBD teams should encourage a patient-centered approach when caring for their IBD patients. This requires awareness of patients' needs and expectations, especially in treatment-related decision-making. Previous studies have shown that IBD patients desire to be actively involved in the decision-making process ${ }^{(24,31)}$ and are mostly open to learning and participating actively in their treatment.

It must be emphasized that not all treatment decisions can be shared with the patient, and not all patients will be able to make such shared decisions. Shared medical decision-making requires patients to have a basic understanding of the disease and treatment options, in addition to their interest in participating in treatment discussions. Siegel ${ }^{(32)}$ suggests applying some basic questions to assess whether the subject to be discussed can be considered for shared decision-making. Some of the questions evaluate the consequences associated with the choice, or whether the patient would like to be part of a shared medical decision. Moreover, the decision needs to be preference sensitive ${ }^{(32)}$, such as in the choice of biological therapy, evaluated in our research.

In a situation wherein a wide variety of treatment options with different modes of administration and different therapeutic regimes exist, with the efficacy of the medications remaining similar, patient's adaptation to treatment is essential. Greater flexibility in the scheduling of medications, and convenience of application are the main advantages associated with SC medications, while greater contact with the doctor and fewer infusions are the main attractions of IV medications. Choosing the treatment that best fits the patient's routine is the key to success.

This study has some limitations. Firstly, this was a crosssectional study and the number of subjects enrolled may appear to be small, although this sample was representative of the population served by our center. Second, about 141 patients were excluded due to previous or current use of biological therapy, most of them were CD patients $(68.79 \%)$, which explains the higher proportion of patients with UC in the study. The greater use of biological therapy and immunomodulators may also be related to the fact that our center is predominantly manned by IBD specialists. Third, the study sample represents the population served in an IBD referral center in the public healthcare system, which is comprised of patients with lower levels of education and income and may not be representative of the entire population with IBD in Brazil. Despite this, national data show lower levels of education of the Brazilian population compared to study participants, illiteracy rates around $6.8 \%$, high school education $27 \%$, and college education $16.5 \%{ }^{(33)}$. In addition, we must mention that we used a questionnaire formulated by the study authors, not validated for the assessment of the patient's preference through the therapy administration route. Future studies should include a larger study sample and include patients of varied demographics to assess their therapeutic preferences.

\section{CONCLUSION}

Brazil is experiencing an emerging burden of IBD and understanding the patient's preference is of paramount importance. Brazilian IBD patients naive to biological therapy preferred the oral over the SC and IV routes. Most patients considered their doctor's opinion when choosing their medications. IBD teams, for ensuring the best possible outcomes for IBD patients, should provide comprehensive treatment options, clearly communicate the risks and benefits related to medications, and involve the patient in the decision-making process.

\section{ACKNOWLEDGEMENTS}

We thank Eloisa Elena Pascoalinotte from Botucatu Medical School at São Paulo State University (UNESP) for her valuable help in statistical analysis. We thank Giédre Soares Prates Herrerias for her valuable help in data collection. We thank Brazilian National Council for Scientific and Technological Development (CNPq) for student scholarship (grant \# ID42174) offered to the student Adhan Amenomori Wu.

\section{Authors' contribution}

All authors contributed to this manuscript. Wu AA, Barros JR, Baima JP, Saad-Hossne R, Sassaki LY contributed to the conception and design of the study, acquisition, analysis and interpretation of data, drafting the article, revising it critically for important intellectual content, and final approval of the version to be submitted. Ramdeen M contributed to the analysis and interpretation of data, drafting the article, revising it critically for important intellectual content, and final approval of the version to be submitted.

\section{Orcid}

Adhan Amenomori Wu: 0000-0002-9754-4551.

Jaqueline Ribeiro de Barros: 0000-0003-1451-8794.

Madhoor Ramdeen: 0000-0003-4213-2899.

Julio Pinheiro Baima: 0000-0002-4035-3113.

Rogerio Saad-Hossne: 0000-0002-8166-0304.

Ligia Yukie Sassaki: 0000-0002-7319-8906. 
Wu AA, Barros JR, Ramdeen M, Baima JP, Saad-Hossne R, Sassaki LY. Fatores associados com a escolha da terapia nos pacientes com doença inflamatória intestinal no Brasil. Arq Gastroenterol. 2020. Ahead of print.

RESUMO - Contexto - A terapia biológica e os novos medicamentos revolucionaram o tratamento da doença inflamatória intestinal. A escolha do medicamento deve ser compartilhada com o paciente, visando maior satisfação, adesão e, consequentemente, desfecho clínico favorável. Objetivo - Este estudo teve como objetivo avaliar as preferências do paciente na escolha de sua terapia e os fatores que influenciaram essa escolha. Métodos - Este estudo transversal incluiu 101 pacientes ambulatoriais com doença de Crohn ou retocolite ulcerativa. Os critérios de inclusão foram idade $\geq 18$ anos e nenhuma exposição prévia à terapia biológica. A preferência dos pacientes foi avaliada por meio de perguntas que abordaram o modo de administração preferido (oral, subcutâneo ou intravenoso) e os fatores que determinaram a escolha do medicamento (eficácia, indicação médica, medo da injeção, conveniência, modo de aplicação e opinião pessoal do médico). Resultados - A idade média foi de 43,6 $\pm 13,5$ anos, $75,3 \%$ eram mulheres e $81,2 \%$ eram portadores de retocolite ulcerativa. Em relação ao modo de administração, a maioria dos pacientes preferiu os medicamentos orais (87,1\%), seguidos dos endovenosos $(6,93 \%)$ e subcutâneos $(5,94 \%)$. Os motivos foram "prefiro aplicar em casa" $(42,57 \%)$, "tenho mais liberdade com essa medicação" (36,63\%), "não gosto de autoaplicação" (29,70\%) e "acredito que funcione melhor" (19,80\%). Pacientes jovens e pacientes em atividade clínica preferiram a via intravenosa em comparação com a via oral $(P<0,05)$. A opinião do médico $(98 \%)$ foi um fator importante associado à escolha do medicamento.

Conclusão - A via oral foi preferida e a maioria dos pacientes levou em consideração a opinião do seu médico na escolha do medicamento.

DESCRITORES - Terapia biológica. Vias de administração de medicamentos. Colite ulcerativa. Doença de Crohn. Doenças inflamatórias intestinais.

\section{REFERENCES}

1. Rutgeerts P, Sandborn WJ, Feagan BG, Reinisch, W, Olson A, Johanns J, et al Infliximab for Induction and Maintenance Therapy for Ulcerative Colitis. N Eng J Med. 2005;353:2462-76. DOI: 10.1056/NEJMoa050516

2. Sandborn WJ, van Assche G, Reinisch W, Colombel JF, D'Haens G, Wolf DC, et al. Adalimumab Induces and Maintains Clinical Remission in Patients with Moderate-To-Severe Ulcerative Colitis. Gastroenterology. 2012;142:257-65. DOI 10.1053/j.gastro.2011.10.032

3. Loftus Jr EV, Colombel JF, Feagan BG, Vermeire S, Sandborn WJ, Sands BE, et al. Long-term Efficacy of Vedolizumab for Ulcerative Colitis. J Crohns Colitis 2017;11:400-11. DOI: 10.1093/ecco-jcc/jjw177

4. Sandborn WJ, Su C, Sands BE, D'Haens GR, Vermeire S, Schreiber S, et al Tofacitinib as Induction and Maintenance Therapy for Ulcerative Colitis. N Engl J Med. 2017;376:1723-36. DOI: 10.1056/NEJMoa1606910

5. Reinisch W, Gibson PR, Sandborn WJ, Feagan BG, Strauss R, Johanns J, et al. Long-Term Benefit of Golimumab for Patients with Moderately to Severely Active Ulcerative Colitis: Results From the PURSUIT-Maintenance Extension. J Crohns Colitis. 2018;12:1053-66. DOI: 10.1093/ecco-jcc/jjy079

6. Rutgeerts P, Diamond RH, Bala M, Olson A, Lichtenstein GR, Bao W, et al Scheduled Maintenance Treatment with Infliximab Is Superior to Episodic Treatment for the Healing of Mucosal Ulceration Associated with Crohn's Disease. Gastrointest Endosc. 2006;63:433-42. DOI: 10.1016/j.gie.2005.08.011

7. Sandborn WJ, Feagan BG, Stoinov S, Honiball PJ, Rutgeerts P, Mason D, et al. Certolizumab Pegol for the Treatment of Crohn's Disease. Engl J Med. 2007;357:228-38. DOI: 10.1056/NEJMoa067594

8. Rutgeerts P, Van Assche G, Sandborn WJ, Wolf DC, Geboes K, Colombel JF, et al. Adalimumab Induces and Maintains Mucosal Healing in Patients with Crohn's Disease: Data from the EXTEND Trial. Gastroenterology. 2012;142:1102-11. DOI: $10.1053 /$ j.gastro.2012.01.035

9. Vermeire S, Loftus Jr EV, Colombel JF, Feagan BG, Sandborn WJ, Sands BE Long-term Efficacy of Vedolizumab for Crohn's Disease. J Crohns Colitis. 2017;11:412-24. DOI: 10.1093/ecco-jcc/jjw176

10. Feagan BG, Sandborn WJ, Gasink C, Jacobstein D, Lang Y, Friedman JR, et al. Ustekinumab as Induction and Maintenance Therapy for Crohn's Disease. N Engl J Med. 2016;375:1946-60. DOI: 10.1056/NEJMoa1602773.

11. Present DH, Rutgeerts P, Targan S, Hanauer SB, Mayer L, van Hogezand RA et al. Infliximab for the Treatment of Fistulas in Patients with Crohn's Disease N Engl J Med. 1999;340:1398-405. DOI: 10.1056/NEJM199905063401804

12. Colombel JF, Schwartz DA, Sandborn WJ, Kamm MA, D'Haens G, Rutgeerts P, et al. Adalimumab for the treatment of fistulas in patients with Crohn's disease. Gut. 2009;58:940-8. DOI: 10.1136/gut.2008.159251

13. Schreiber S, Lawrance IC, Thomsen OØ, Hanauer SB, Bloomfield R, Sandborn WJ. Randomised clinical trial: certolizumab pegol for fistulas in Crohn's disease - subgroup results from a placebo-controlled study. Aliment Pharmacol Ther 2011;33:185-93. DOI: 10.1111/j.1365-2036.2010.04509.x
14. Feagan BG, Schwartz D, Danese S, Rubin DT, Lissoos TW, Xu J, et al. Efficacy of Vedolizumab in Fistulising Crohn's Disease: Exploratory Analyses of Data from GEMINI 2. J Crohns Colitis. 2018;12:621-6. DOI: 10.1093/eccojcc/jjy019

15. Mahlich J, Matsuoka K, Sruamsiri R. Shared Decision Making and Treatment Satisfaction in Japanese Patients with Inflammatory Bowel Disease. Dig Dis 2017;35:454-62. DOI: 10.1159/000471795

16. O' Morain C, Tobin A, Leen E, Suzuki Y, O' Riordan T. Criteria of case definition in Crohn's disease and ulcerative colitis. Scand J Gastroenterol Suppl. 1989;170:711. DOI: $10.3109 / 00365528909091340$

17. Best WR, Becktel JM, Singleton JW, Kern Jr F. Development of a Crohn's disease activity index. Gastroenterology. 1976;70:439-44.

18. Silverberg MS, Satsangi J, Ahmad T, Arnott ID, Bernstein CN, Brant SR, et al. Toward an integrated clinical, molecular and serological classification of inflammatory bowel disease: Report of a Working Party of the 2005 Montreal World Congress of Gastroenterology. Can J Gastroenterol. 2005;19:36.36. DOI: $10.1155 / 2005 / 269076$

19. Schroeder KW, Tremaine WJ, Ilstrup DM. Coated oral 5-aminosalicylic acid therapy for mildly to moderately active ulcerative colitis. A randomized study. N Engl J Med. 1987;317:1625-9. DOI: 10.1056/NEJM198712243172603

20. Satsangi J, Silverberg MS, Vermeire S, Colombel JF. The Montreal classification of inflammatory bowel disease: controversies, consensus, and implications. Gut. 2006;55:749-53. DOI: 10.1136/gut.2005.082909

21. Vavricka SR, Bentele N, Scharl M, Rogler G, Zeitz J, Frei P, et al. Systematic assessment of factors influencing preferences of Crohn's disease patients in selecting an anti-tumor necrosis factor agent (CHOOSE TNF TRIAL). Inflamm Bowel Dis. 2012;18:1523-30. DOI: 10.1002/ibd.21888

22. Williams EL, Edwards CJ. Patient preferences in choosing anti-TNF therapies-R1. Rheumatology (Oxford). 2006;45:1575-6. DOI: 10.1093/rheumatology/ kel369

23. Chilton F, Collett RA. Treatment choices, preferences and decision making by patients with rheumatoid arthritis. Musculoskeletal Care. 2008;6:1-14. DOI $10.1002 / \mathrm{msc} .110$.

24. Cha JM, Park DI, Park SH, Shin JE, Kim WS, Yang S-K. Physicians Should Provide Shared Decision-Making for Anti-TNF Therapy to Inflammatory Bowel Disease Patients. J Korean Med Sci. 2017;32:85-94. DOI: 10.3346/ jkms.2017.32.1.85

25. Allen PB, Lindsay $\mathrm{H}$, Tham TC. How do patients with inflammatory bowel disease want their biological therapy administered? BMC Gastroenterol. 2010;10:1-6. DOI: 10.1186/1471-230X-10-1

26. Almario CV, Keller MS, Chen M, Lasch K, Ursos L, Shklovskaya J, et al. Optimizing Selection of Biologics in Inflammatory Bowel Disease: Development of an Online Patient Decision Aid Using Conjoint Analysis. Am J Gastroenterol. 2018;113:58-71. DOI: 10.1038/ajg.2017.470 
27. Hazlewood GS, Pokharel G, Deardon R, Marshall DA, Bombardier C, Tomlinson $\mathrm{G}$, et al. Patient preferences for maintenance therapy in Crohn's disease: A discrete-choice experiment. PLoS One. 2020;15:e227635. DOI: 10.1371/journal. pone. 0227635

29. IOM. Crossing the quality chasm: A new health system for the 21 st century. Washington, DC: National Academy Press; 2001. DOI: 10.17226/10027

28. Kemp K, Dibley L, Chauhan U, Greveson K, Jäghult S, Ashton K, et al. 2nd N-ECCO Consensus Statements on the European Nursing Roles in Caring for Patients with Crohn's Disease or Ulcerative Colitis. J Crohn's Colitis. 2018;12:76076. DOI: 10.1016/j.crohns.2013.06.004
30. IOM. Clinical practice guidelines we can trust. Washington, DC: The National Academies Press; 2011. DOI: 10.17226/13058

31. Baars JE, Markus T, Kuipers EJ, Van Der Woude CJ. Patients' preferences regarding shared decision-making in the treatment of inflammatory bowel disease: results from a patient-empowerment study. Digestion. 2010;81:113-9. DOI: $10.1159 / 000253862$

32. Siegel CA. Shared decision making in inflammatory bowel disease: helping patients understand the tradeoffs between treatment options. Gut. 2012;61:459e465. DOI: 10.1136/gutjnl-2011-300988

33. IBGE. [Internet]. [Accessed 2020 May 25]. Available from: https://educa.ibge. gov.br/jovens/conheca-o-brasil/populacao/18317-educacao.html. 